\title{
Yarı Kurak İklim Şartlarında Yetiștirilen Patates (Solanum tuberosum L.) Çeşitlerinde Dikim Zamanının Belirlenmesi
}

\author{
Hüseyin ARSLAN* \\ Siirt Üniversitesi, Ziraat Fakültesi, Tarla Bitkileri Bölümü, Siirt, TÜRKIYYE
}

\begin{tabular}{l}
\hline \multicolumn{1}{c}{ Geliş Tarihi/Received: 10.01.2019 Kabul Tarihi/Accepted: 26.02 .2019} \\
\hline ORCID ID \\
(1D) orcid.org/0000-0001-7221-7952 \\
"Sorumlu Yazar/Corresponding Author: huarslan@siirt.edu.tr
\end{tabular}

Öz: Bu araștırmada, Siirt ili iklim koşullarında bazı patates çeșitlerinde uygun dikim zamanının belirlenmesi amaçlanmıștır. Çalışma; Siirt Üniversitesi, Ziraat Fakültesi, Araştırma ve Uygulama Arazisi'nde 2017-2018 yıllarında yürütülmüş olup, araștırmada bitkisel materyal olarak Alegria, Borvina ve Soraya patates çeșitleri kullanılmıștır. Dikim zamanları olarak ise, 5 farklı dikim zamanı (2017 yılında 14 Şubat, 05 Mart, 27 Mart, 16 Nisan ve 04 Mayıs; 2018 yılında ise 16 Şubat, 05 Mart, 25 Mart, 16 Nisan ve 02 Mayıs) ele alınmıştır. Araştırmada, tarla denemeleri tesadüf bloklarında bölünmüş parseller deneme desenine göre 4 tekerrürlü olarak yürütülmüştür. Çalışmada; dekara yumru verimi, bitki başına yumru sayısı, bitki başına yumru ağırlı̆̆ 1 ve ortalama yumru ağırlı̆̆ gibi bazı tarımsal parametreler incelenmiştir. Araştırma sonuçlarına göre, patates tarımında dikim zamanının ve çeşit seçiminin verim üzerinde çok önemli bir etkiye sahip olduğu; incelenen parametrelerin sıcaklıklarda meydana gelen küçük değişimlere dahi tepki gösterdiği; en yüksek verimin Mart ayı içerisinde yapılan dikimlerden alındığı tespit edilmiștir. Araștırmada her iki yılda da en yüksek yumru verimi (sırasıyla, 4001.38 ve $3066.13 \mathrm{~kg}$ $\mathrm{da}^{-1}$ ) Soraya çeşidinden elde edilmiştir. Çalışma sonucunda, Siirt ili ve benzeri iklim koşullarında patates dikimlerinin Mart ayı içerisinde yapılması gerektiği ve "Soraya" çeşidinin rahatlıkla önerilebileceği sonucuna varılmıştır.

Anahtar Kelimeler: Siirt, patates, dikim zamanı, çeşit, iklim, verim

\section{Determination of Sowing Time in Potatoes (Solanum tuberosum L.) Cultivated in Semi-Arid Climate Conditions}

\begin{abstract}
In this study, it was aimed to determine the appropriate planting time in some potato varieties in the climate conditions of Siirt province. The study was carried out in Siirt University, Faculty of Agriculture, Research and Application Field between the years of 2017-2018. In this study, Alegria, Borvina and Soraya potatoes varieties were used as plant material. In terms of planting times, 5 different planting times (February 14, March 05, March 27, April 16 and May 04 in 2017, and February 16, March 05, March 25, April 16 and May 02 in 2018) were discussed. In the study, field trials were carried out with 4 replications according to divided parcels in randomized blocks design. In the study, some agricultural parameters such as tuber yield per square kilometer, the number of tubers per plant, tuber weight per plant and average tuber weight were examined. According to the results of the study, it was found that planting time and variety selection in potato farming had a significant effect on yield, where the parameters examined react to even small changes in temperature, and it was determined that the highest yield was obtained from the plantings in March. In the study, the highest tuber yield in both years (4001.38 and $3066.13 \mathrm{~kg} \mathrm{da}^{-1}$, respectively) was obtained from Soraya variety. As a result of the study, it was concluded that the planting of potatoes should be made in March in Siirt province and in similar climatic conditions and Soraya variety could easily be suggested.
\end{abstract}

Keywords: Siirt, potatoes, planting time, variety, climate, yield 


\section{Giriş}

Dünyada 8000 yıldan beri tarımı yapılan patates, Solanum cinsine ait olup, 2000 türü vardır. Bu 2000 türün içerisinde 160 ila 180 türden yumru üretimi yapılmaktadır. Bunlardan 8 tür insan beslenmesinde kullanılmaktadır. Solanum cinsine ait insan beslenmesinde kullanılan ve yaygın olarak yetiştiriciliği yapılan tür Solanum tuberosum'dur. Birim alanda yüksek verime sahip olan patates insan ve hayvan beslenmesinde önemli bir yere sahiptir. Aynı zamanda gıda sanayi için de önemli bir ham maddedir. Kullanım alanının geniş olması ve farklı iklimlerde yetişebilmesinden dolayı çok geniş bir coğrafyada üretilmektedir. Patates aynı zamanda, nişasta ve ispirto endüstrisinin önemli bir hammaddesi olup, nişastasından glikoz ve dekstrin elde edilmektedir. Diğer yandan, dokumacılıkta ipliklerin birbirine yapışmaması ve pamuklaşmayı önlemesi için haşıl olarak da kullanılmaktadır (Rowe, 1993; Tunçtürk, 2006; Yılmaz ve ark., 2006; Kolsarıc1, 2011; Kara, 2016).

Aslında bir serin iklim bitkisi olan patates için sıcaklık, yetiştiricilikte sınırlayıcı bir faktördür. Yumru büyümesi, $10{ }^{\circ} \mathrm{C}$ 'nin altındaki ve $30{ }^{\circ} \mathrm{C}$ 'nin üstündeki sıcaklıklarda durmaktadır. Optimum verim, günlük ortalama sıcaklıkların 18 ila $20{ }^{\circ} \mathrm{C}$ olduğu durumlarda elde edilir. Patates, Türkiye'de Akdeniz ve Ege kıyı bölgelerinde, diğer Akdeniz ülkelerinde olduğu gibi turfanda olarak kış ve bahar aylarında üretilmektedir. Turfanda patates yetiştiriciliğinde, bölgelere bağlı olarak dikimler Aralık ayından Mart ayının başına kadar geçen süre içerisinde yapılmaktadır. Hasatlar yine bölgeler itibari ile Nisan ortasından Haziran sonuna kadar yapılabilmektedir. Turfanda patates yetiştirme döneminde dikim zamanları, ilk gelişme devreleri kısa gün (10- 12 saat) ve düşük sıcaklıklara (10-15 ${ }^{\circ} \mathrm{C}$ ) denk gelmekte; yetişme süresi ise 80-100 gün arasında değişmektedir (Arığlu ve ark., 2010; Çalışkan ve ark., 2010a; Anonymous, 2018).

Birleşmiş Milletler Gıda ve Tarım Örgütü (FAO, Food and Agriculture Organization) 2017 yılı verilerine göre, dünyada 388.191 .000 ton patates üretildiği tahmin edilmektedir. Çin, 99.205.580 ton ile birinci sirada yer alırken, Türkiye 4.800 .000 ton üretimi ile dünya patates üretiminde 14. sırada yer almaktadır (Anonymous, 2019). Niğde 835.200 ton patates üretimi ile Türkiye patates üretiminde birinci sirada (üretilen patatesin $\%$ 17.4'ü) yer almaktadır. Türkiye İstatistik Kurumu verileri incelendiğinde, Siirt ilinde patates üretiminin ise olmadığ görülmektedir.
Türkiye'de son yıllarda patates fiyatlarındaki artışlar göz önüne alındığında patates üretiminin iç talebi karşılamada yetersiz olduğu kanaatini oluşturmaktadır. Patates fiyatlarının tüketicinin lehine olacak şekilde düşmesi için üretimin ya da verimin arttırılması büyük önem taşımaktadır. Bunun için yetiştirme teknikleri konusunda bilimsel çalışmaların arttırılması gerekmektedir. Özellikle patates üretim alanlarının arttırılması ve bu alanlardan yüksek verim elde edilebilmesi için uygun dikim zamanının belirlenmesinin, verimi yüksek çeşitlerinde tespit edilmesi önemli bir konu olarak karşımıza çıkmaktadır. Türkiye'de patates yetiştiriciliğinin yapıldı ğ farklı ekolojilerde, uygun dikim zamanı ve çeşitlerin belirlenmesine yönelik çalışmalar yapılmış; bu çalışmalarda, verim üzerinde hem uygun çeşit seçiminin hem de dikim zamanının önemli olduğu tespit edilmiştir (Samanc1 ve ark., 2003; Khan ve ark., 2011; Karaca Öner ve Aytaç, 2016).

Bu araştırmada; karasal iklimin hüküm sürdüğü Siirt ili koşullarında bazı patates çeşitlerinde uygun dikim zamanının belirlenmesi amaçlanmıştır.

\section{Materyal ve Yöntem}

Bu çalışma; Siirt ili iklim koşullarında bazı patates çeşitlerinde farklı dikim tarihlerinin verim ve verim unsuları üzerine etkisini belirlemek amacıyla, 2017 ve 2018 patates yetiştirme sezonunda, Siirt Üniversitesi, Ziraat Fakültesi deneme alanında yürütülmüştür. Araştırmada; Alegria, Borvina ve Soraya patates çeşitleri bitkisel materyal olarak kullanılmış olup; çeşitlerin bazı özellikleri Tablo 1 'de verilmiştir.

Tablo 1. Araştırmada kullanılan tescilli patates çeşitlerinin özellikleri

\begin{tabular}{lccc}
\hline Özellik & Soraya & Borwina & Alegria \\
\hline $\begin{array}{l}\text { Olgunluk } \\
\text { grubu }\end{array}$ & Erkenci & $\begin{array}{c}\text { Orta } \\
\text { erkenci }\end{array}$ & Orta erkenci \\
\hline $\begin{array}{l}\text { Kabuk } \\
\text { rengi }\end{array}$ & Sarı & Parlak sarı & Parlak sarı \\
\hline $\begin{array}{l}\text { Tüketim } \\
\text { şekli }\end{array}$ & Yemeklik & Yemeklik & K1zartmalık \\
\hline $\begin{array}{l}\text { Yumru } \\
\text { şekli }\end{array}$ & Oval & Oval & Oval \\
\hline $\begin{array}{l}\text { Tescil } \\
\text { tarihi }\end{array}$ & 19.04 .2016 & 05.04 .2011 & 05.04.2011 \\
\hline
\end{tabular}

Siirt ilinde genellikle karasal iklim hâkimdir. Doğu ve kuzey bölgelerinde kışlar daha sert ve yağışl1, güney ve güneybatı bölgelerinde ise kışın 1lık iklimine karşılık, yazlar daha sıcak ve kuraktır. Siirt ilinin uzun yıllar ve araştırma yılları iklim verileri Tablo 2'de verilmiştir. Araştırmada 
Tablo 2. Siirt ili, patates yetiştirme sezonundaki uzun yıllar (1938-2017) ve araştırma yıllarına ait bazı iklim verileri

\begin{tabular}{|c|c|c|c|c|c|c|}
\hline Aylar & Yillar & $\begin{array}{c}\text { Ortalama } \\
\text { maksimum } \\
\text { sicaklik }\left({ }^{\circ} \mathrm{C}\right)\end{array}$ & $\begin{array}{c}\text { Ortalama } \\
\text { minimum } \\
\text { sicaklik }\left({ }^{\circ} \mathrm{C}\right)\end{array}$ & $\begin{array}{l}\text { Ortalama } \\
\text { sicaklik } \\
\left({ }^{\circ} \mathrm{C}\right)\end{array}$ & $\begin{array}{c}\text { Nispi nem } \\
(\%)\end{array}$ & $\begin{array}{c}\text { Toplam } \\
\text { yağ1ş } \\
(\mathrm{mm})\end{array}$ \\
\hline & 2017 & 7.4 & -0.2 & 3.0 & 65.9 & 49.4 \\
\hline \multirow[t]{3}{*}{ Ocak } & 2018 & 9.7 & 2.7 & 5.7 & 70.5 & 57.6 \\
\hline & Uzun yillar & 6.5 & -0.5 & 2.6 & 68.8 & 96.8 \\
\hline & 2017 & 7.9 & -1.4 & 2.7 & 64.9 & 45.6 \\
\hline \multirow[t]{3}{*}{ Şubat } & 2018 & 12.9 & 4.8 & 8.2 & 67.7 & 73.6 \\
\hline & Uzun yillar & 8.7 & 0.4 & 4.2 & 64.2 & 97.5 \\
\hline & 2017 & 14.7 & 5.3 & 9.6 & 63.9 & 118.8 \\
\hline \multirow[t]{3}{*}{ Mart } & 2018 & 18.6 & 9.3 & 13.7 & 55.9 & 47.2 \\
\hline & Uzun yıllar & 13.2 & 3.9 & 8.3 & 53.7 & 111.1 \\
\hline & 2017 & 19.8 & 9.2 & 14.0 & 59.5 & 118.1 \\
\hline \multirow[t]{3}{*}{ Nisan } & 2018 & 22.7 & 11.3 & 16.8 & 47.6 & 60.8 \\
\hline & Uzun yıllar & 19.1 & 8.9 & 13.7 & 50.4 & 104.7 \\
\hline & 2017 & 25.1 & 13.9 & 19.5 & 51.7 & 74.8 \\
\hline \multirow[t]{3}{*}{ Mayıs } & 2018 & 25.7 & 14.9 & 19.8 & 59.1 & 146.8 \\
\hline & Uzun yillar & 25.2 & 13.5 & 19.3 & 41.5 & 62.0 \\
\hline & 2017 & 33.2 & 20.0 & 26.9 & 29.5 & 0 \\
\hline \multirow[t]{3}{*}{ Haziran } & 2018 & 33.4 & 21.0 & 27.4 & 31.7 & 3 \\
\hline & Uzun yıllar & 32.1 & 18.9 & 26.0 & 24.1 & 8.7 \\
\hline & 2017 & 39.1 & 24.8 & 32.3 & 19.0 & 0 \\
\hline \multirow[t]{2}{*}{ Temmuz } & 2018 & 38.7 & 25.4 & 32.3 & 20.1 & 0.6 \\
\hline & Uzun yillar & 36.9 & 23.4 & 30.6 & 18.1 & 1.6 \\
\hline
\end{tabular}

yetiştirme dönemine ait iklim verileri incelendiğinde, deneme yıllarına ait sıcaklık ortalamalarının (maksimum, minimum ve ortalama) uzun yıllar sicaklık ortalamalarına göre daha yüksek olduğu görülmektedir. Sadece 2017 y1lı Şubat ayı ortalama minimum ve ortalama sıcaklığın uzun yıllara göre daha düşük olmuştur. Araştırma yılları ortalama nispi nem değerlerinin uzun yıllar ortalamasına benzerlik gösterdiği görülmüştür. Yağış verilerine bakıldığında ise; deneme yıllarına ait Ocak, Şubat, Haziran ve Temmuz aylarına ait toplam yağış miktarlarının uzun yıllara göre daha düşük olduğu, Mart 2017, Nisan 2017, Mayıs 2017 ve Mayıs 2018 aylarında ise düşen yağış miktarının uzun yıllara ait yağış miktarlarından daha yüksek olduğu saptanmıştır.

Araştırmada, denemeler kurulmadan önce alınan toprakların analiz sonuçları Tablo 3'te sunulmuştur. Tablo 3 'ten de görüleceği üzere, araştırma yeri toprağının kumlu-kil tekstürlü, nötr karakterli ve tuzluluk probleminin olmadığı; toprakların kireç içeriğinin az kireçli, organik madde içeriğinin az, alınabilir fosfor içeriğinin çok az ve alınabilir potasyum kapsamının ise yeterli düzeyde olduğu belirlenmiştir.

Araştırmada, 3 farklı patates çeşidi (Alegria, Borvina ve Soraya)'nde 5 farklı dikim zamanı araştırma konusu olarak ele alınmıştır. Buna göre, yaklaşık 20 gün aralıklarla dikim zamanları belirlenmiş olup, araştırmada ele alınan dikim zamanları aşağıda verildiği şekilde planlanmıştır:
1. Dikim zamanı: Şubat ayının ortası

2. Dikim zamanı: Mart ayının ilk haftası

3. Dikim zamanı: Mart ayının son haftası

4. Dikim zamanı: Nisan ayının ortası

5. Dikim zamanı: Mayıs ayının ilk haftası

Tablo 3. Araştırma yeri topraklarının bazı fiziksel ve kimyasal özellikleri $(0-20 \mathrm{~cm})^{*}$

\begin{tabular}{lc}
\hline Toprak özelliği & Değeri \\
\hline Kil, \% & 43.51 \\
Kum, \% & 47.99 \\
$\mathrm{Silt}, \%$ & 8.49 \\
$\mathrm{pH}$ & 6.89 \\
Elektriksel iletkenlik, $\mathrm{mS} \mathrm{cm}^{-1}$ & 463 \\
Kireç, \% & 0.5 \\
Organik madde, \% & 1.02 \\
Alınabilir fosfor, $\mathrm{kg} \mathrm{P}_{2} \mathrm{O}_{5} \mathrm{da}^{-1}$ & 2.2 \\
Alınabilir potasyum, $\mathrm{kg} \mathrm{K}_{2} \mathrm{O} \mathrm{da}^{-1}$ & 86 \\
\hline
\end{tabular}

": Analizler; Siirt Üniversitesi, Bilim ve Teknoloji Uygulama ve Araştırma Merkezi Laboratuvarı'nda yapılmıştır.

Tesadüf bloklarında bölünmüş parseller deneme desenine göre dört tekerrürlü olarak yürütülen araştırmada; dikim zamanları ana parselleri, çeşitler ise alt parselleri oluşturmuştur. Buna göre patates çeşitlerinin dikimi 2017 ve 2018 yılları sırasına göre; 1. dikim zamanında 14 ve 16 Şubat, 2. dikim zamanında 05 Mart, 3. dikim zamanında 27 ve 25 Mart, 4. dikim zamanında 16 Nisan ve 5. dikim zamanında ise 04 ve 02 Mayıs tarihlerinde gerçekleştirilmiştir. Araştırmada, bütün parsellere dikim ile beraber dekara saf olarak $4.5 \mathrm{~kg}$ azot ve 
$11.5 \mathrm{~kg}$ fosfor ( $25 \mathrm{~kg} \mathrm{da}^{-1}$ diamonyum fosfat), boğaz doldurma öncesinde dekara $23 \mathrm{~kg}$ saf azot (50 kg $\mathrm{da}^{-1}$ üre) uygulanmıştır. Yetişme sezonu boyunca dikim zamanlarına bağlı olarak bitkinin ihtiyacı olan su, damla sulama yöntemi ile verilmiştir. Yabanc1 otlar görüldüğünde elle mücadelesi yapılmıştır.

Hasatlar; 1., 2. ve 3. dikim zamanları için 24-25 Haziran 2017/2018, 4. ve 5. dikim zamanları için 20-25 Temmuz 2017/2018 tarihlerinde yapılmıştır.

Çalışmada, Anonim (2001) esas alınarak; bitki başına yumru sayısı (adet bitki $\left.{ }^{-1}\right)$, bitki başına ortalama yumru verimi ( $\mathrm{g}$ bitki ${ }^{-1}$ ), ortalama yumru ağırlığı (g) ve dekara yumru verimi $\left(\mathrm{kg} \mathrm{da}{ }^{-1}\right)$ parametreleri tespit edilmiştir.

Elde edilen iki yıllık verilerle varyans analizi öncesi homojenlik testi yapılmış olup, yıllar arasında homojenlik bulunmadığ 1 için yıllara ait varyans analizleri ayrı ayrı yapılmış; ortalamalar arasındaki farklılıklar LSD testine göre gruplandırılmıştır (Yurtsever, 1984).

\section{Bulgular}

\subsection{Yumru verimi}

Tablo 4 incelendiğinde 2017 yılında, yumru verimi bakımından; çeşit ve dikim zamanları (DZ) arasında istatistiki olarak $\mathrm{p}<0.01$ düzeyinde önemli farklılık görülmüştür. Çalışmada, 2017 yılında ekim zamanlarının ortalaması olarak en yüksek yumru verimi $4001.38 \mathrm{~kg}$ ile Soraya çeşidinden, en düşük verim ise $3528.81 \mathrm{~kg} \mathrm{da}^{-1}$ ile Borwina çeşidinden elde edilmiştir. Dikim zamanlarına bağlı olarak verim ortalamalarının değiștiği, ilk ve son iki dikimlerde verimlerin, diğer iki dikim (3. ve 4. DZ) zamanına göre daha düşük olduğu görülmüştür. Diğer yandan çeşitlerin dikim zamanına bağlı olarak gösterdikleri tepkilerin birbirinden farklı olduğu belirlenmiş, bunun sonucunda çeşit x dikim zamanı interaksiyonu istatistiki açıdan önemli $(\mathrm{p}<0.05)$ bulunmuştur (Tablo 4).

Yumru verimlerine ait 2018 y1lı verileri incelendiğinde, çeşit ve dikim zamanlarının patates yumru verimini istatistiki olarak çok önemli $(p<0.01)$ düzeyde etkilediği görülmüştür.

Tablo 4. Farklı patates çeşitlerinde dikim zamanlarına göre belirlenen yumru verimleri $\left(\mathrm{kg} \mathrm{da}^{-1}\right)^{1}$

\begin{tabular}{|c|c|c|c|c|c|c|c|}
\hline \multirow{2}{*}{ Y1l } & \multirow{2}{*}{ Çeşitler } & \multicolumn{5}{|c|}{ Dikim zamanı } & \multirow{2}{*}{ Ortalama } \\
\hline & & 1 & 2 & 3 & 4 & 5 & \\
\hline \multirow{5}{*}{2017} & Alegria & $2551.43 \mathrm{ef}$ & $6070.48 \mathrm{~b}$ & $5578.75 \mathrm{bc}$ & $3325.71 \mathrm{~d}$ & $1001.90 \mathrm{~g}$ & $3705.65 \mathrm{~b}$ \\
\hline & Borwina & $1985.71 \mathrm{f}$ & $5880.00 \mathrm{bc}$ & $5491.67 \mathrm{c}$ & 3076.19 de & $1210.48 \mathrm{~g}$ & $3528.81 \mathrm{~b}$ \\
\hline & Soraya & $3034.29 \mathrm{de}$ & $6967.62 \mathrm{a}$ & $5518.33 \mathrm{bc}$ & $3280.00 \mathrm{~d}$ & $1206.67 \mathrm{~g}$ & $4001.38 \mathrm{a}$ \\
\hline & Ortalama & $2523.81 \mathrm{~B}$ & $6306.03 \mathrm{~A}$ & $5529.58 \mathrm{~A}$ & $3227.30 \mathrm{~B}$ & $1139.68 \mathrm{C}$ & 3745.28 \\
\hline & LSD $_{\text {Çeșit (Ç }}$ & $16^{* *}, \mathrm{LSD}_{\mathrm{DZ}}$ & $304.30^{* *}, \mathrm{LSI}$ & $x D z=575.02$ & $\mathrm{VK}=\% 10.63$ & & \\
\hline \multirow{5}{*}{2018} & Alegria & 3087.58 & 3149.09 & 3818.57 & 3306.43 & 1187.34 & $2909.80 \mathrm{a}$ \\
\hline & Borwina & 2139.52 & 2362.02 & 3072.94 & 2017.10 & 740.16 & $2066.35 \mathrm{~b}$ \\
\hline & Soraya & 3211.59 & 3938.56 & 4186.31 & 2776.44 & 1217.74 & $3066.13 \mathrm{a}$ \\
\hline & Ortalama & $2812.90 \mathrm{~B}$ & $3149.89 \mathrm{~B}$ & $3692.61 \mathrm{~A}$ & $2699.99 \mathrm{~B}$ & $1048.41 \mathrm{C}$ & 2680.76 \\
\hline & \multicolumn{7}{|c|}{$\mathrm{LSD}_{C}=368.30^{* *}, \mathrm{LSD}_{\mathrm{DZ}}=474.67^{* *}, \mathrm{LSD}_{\mathrm{C} x \mathrm{DZ}}=$ Ö.D., DK=\% 21.27} \\
\hline
\end{tabular}

': Aynı grupta, aynı satırda ve aynı sütunda farklı harfle gösterilen ortalamalar arasındaki farklılık istatistiki açıdan önemlidir, DZ: Dikim zamanı, VK: Varyasyon katsayısı, ${ }^{*}: \mathrm{p}<0.05$ seviyesinde önemli, ${ }^{* *}: \mathrm{p}<0.01$ seviyesinde önemli, Ö.D.: Önemli değil

Çeşitlerin verim ortalamaları göz önüne alındığında, dikim zamanlarının ortalaması olarak en yüksek verimin ilk yıl sonuçlarında olduğu gibi Soraya çeșidinden $\left(3066.13 \mathrm{~kg} \mathrm{da}^{-1}\right)$ alınmış olup, Alegria çeşidinin verimi (2909.80 $\left.\mathrm{kg} \mathrm{da}^{-1}\right)$ de Soraya çeşidi ile istatistiki olarak aynı grupta yer aldığı belirlenmiştir. Çalıșmanın ikinci yılında, en düşük yumru verimi Borwina (2066.35 $\mathrm{kg} \mathrm{da}^{-1}$ ) çeşidinden elde edilmiştir. Dikim zamanlarına ait verim ortalamalarına göre 2017 yılında olduğu gibi ilk ve son iki dikimlerde verimlerin, diğer iki dikim (3. ve 4. DZ) zamanına göre daha düşük olduğu görülmüştür (Tablo 4).

Her iki yıla ait verim değerleri incelendiğinde Soraya çeşidinin ön plana çıktığı görülmektedir. Dikim zamanları arasında ise en yüksek verimler ikinci ve üçüncü zamanlardan elde edilmiştir. Çeşit x dikim zamanı interaksiyonu 2018 yılında önemsiz çıkmış olsa da, her iki yılda da Soraya çeşidi ikinci ve üçüncü dikim zamanlarında en yüksek verim değerine ulaşmıştır (Tablo 4).

\subsection{Bitki başına ortalama yumru verimi}

Bitki başına ortalama yumru verimi değerleri incelendiğinde; her iki deneme yllında da araştırmada ele alınan çeșitler ve uygulanan dikim zamanları arasında istatistiki olarak çok önemli $(\mathrm{p}<0.01)$ farklılık görülmüş, çeşit $\mathrm{x}$ dikim zamanı interaksiyonu ise yine her iki yılda da istatistiki açıdan $\mathrm{p}<0.05$ düzeyinde önemli bulunmuştur. Araştırmanın ilk yılında en yüksek bitki başına ortalama yumru verimi $957.03 \mathrm{~g}$ ile Soraya çeşidinden elde edilirken, Soraya çeşidi ile Alegria (885.02 $\mathrm{g} \mathrm{bitki}^{-1}$ ) çeşitlerinin ortalama yumru 
verimleri arasındaki farklılık istatistiki olarak önemsiz bulunmuştur. İlk yıl en düşük bitki başına ortalama verim ise $804.66 \mathrm{~g}$ ile Borwina çeşidinden elde edilmiştir. Çalışmanın ikinci yılında ise, ilk yıla benzer sonuçlar elde edilmiş, en yüksek bitki başına ortalama yumru verimi istatistiki olarak aynı grupta yer alan Alegria (764.43 $\mathrm{g} \mathrm{bitki}^{-1}$ ) ve Soraya (705.29 $\mathrm{g} \mathrm{bitki}^{-1}$ ) çeşitlerinde, en düşük ise Borvina (580.47 $\mathrm{g} \mathrm{bitki}^{-1}$ ) çeşidinden alınmıştır (Tablo 5). Araştırmanın ilk yılında, çeşitlerin ortalaması olarak; en yüksek ortalama bitki başına yumru verimi $1444.00 \mathrm{~g}$ ile 2. dikim zamanından elde edilirken; ikinci y1l en yüksek verimler istatistiki olarak aynı grupta yer alan 5. DZ hariç diğer dikim zamanlarında belirlenmiştir (Tablo 5).

Çeşitlerin bitki başına ortalama yumru verimi bakımından dikim zamanına bağlı olarak gösterdikleri tepki birbirinden farklı olmuş, bu fark da istatistiki açıdan anlamlı bulunmuştur. Çeşit x dikim zamanı interaksiyonu incelendiğinde 2017

Tablo 5. Farklı patates çeşitlerinde dikim zamanlarına göre belirlenen ortalama yumru verimi $\left(\mathrm{g} \mathrm{bitki}^{-1}\right)^{1}$

\begin{tabular}{|c|c|c|c|c|c|c|c|}
\hline \multirow{2}{*}{ Y1l } & \multirow{2}{*}{ Çeşitler } & \multicolumn{5}{|c|}{ Dikim zamanı } & \multirow{2}{*}{ Ortalama } \\
\hline & & 1 & 2 & 3 & 4 & 5 & \\
\hline \multirow{4}{*}{2017} & Alegria & $783.60 \mathrm{de}$ & $1455.60 \mathrm{ab}$ & $1192.28 \mathrm{c}$ & $753.60 \mathrm{de}$ & $240.00 \mathrm{~h}$ & $885.02 \mathrm{ab}$ \\
\hline & Borwina & $490.80 \mathrm{fg}$ & $1258.80 \mathrm{bc}$ & $1354.50 \mathrm{bc}$ & 648.00 ef & $271.20 \mathrm{~h}$ & 804.66 b \\
\hline & Soraya & $706.80 \mathrm{~d}-\mathrm{f}$ & $1617.60 \mathrm{a}$ & $1187.55 \mathrm{c}$ & $889.20 \mathrm{~d}$ & $384.00 \mathrm{gh}$ & $957.03 \mathrm{a}$ \\
\hline & Ortalama & $660.40 \mathrm{C}$ & $1444.00 \mathrm{~A}$ & $1244.78 \mathrm{~B}$ & $763.60 \mathrm{C}$ & $298.40 \mathrm{D}$ & 882.24 \\
\hline \multicolumn{8}{|c|}{$\mathrm{LSD}_{\mathrm{C}}=100.00^{* *}, \mathrm{LSD}_{\mathrm{DZ}}=180.00^{* *}, \mathrm{LSD}_{\mathrm{C} x \mathrm{xZ}}=220.00^{*}, \mathrm{VK}=\% 17.10$} \\
\hline \multirow{5}{*}{2018} & Alegria & $731.15 \mathrm{cde}$ & $779.60 \mathrm{bcd}$ & $1042.20 \mathrm{a}$ & $953.50 \mathrm{ab}$ & $315.70 \mathrm{f}$ & $764.43 \mathrm{a}$ \\
\hline & Borwina & $658.80 \mathrm{de}$ & 643.95 de & $705.35 \mathrm{de}$ & $666.05 \mathrm{de}$ & $228.20 \mathrm{f}$ & $580.47 \mathrm{~b}$ \\
\hline & Soraya & $841.05 \mathrm{a}-\mathrm{d}$ & $931.33 \mathrm{abc}$ & $917.45 \mathrm{abc}$ & $553.72 \mathrm{e}$ & $282.90 \mathrm{f}$ & $705.29 \mathrm{a}$ \\
\hline & Ortalama & $743.67 \mathrm{~A}$ & $784.96 \mathrm{~A}$ & $888.33 \mathrm{~A}$ & $724.42 \mathrm{~A}$ & $275.60 \mathrm{~B}$ & 683.40 \\
\hline & $\mathrm{LSDC}_{\mathrm{C}}=92$ & $\mathrm{SD}_{\mathrm{DZ}}=164$. & ${ }^{*}, \mathrm{LSD}_{\mathrm{C} x \mathrm{xZ}}=$ & $06.65^{*}, \mathrm{DK}=$ & 20.94 & & \\
\hline
\end{tabular}

1: Aynı grupta, aynı satırda ve aynı sütunda farklı harfle gösterilen ortalamalar arasındaki farklılık istatistiki açıdan önemlidir, DZ: Dikim zamanı, VK: Varyasyon katsayısi, ${ }^{*}$ : $p<0.05$ seviyesinde önemli, ${ }^{* *}: \mathrm{p}<0.01$ seviyesinde önemli

yılında en yüksek bitki başına yumru veriminin $1617.60 \mathrm{~g} \mathrm{bitki}^{-1}$ ile ikinci zamanda dikimi yapılan Soraya çeşidinden, en düşük verimin ise $240 \mathrm{~g}$ bitki ${ }^{-}$ ${ }^{1}$ beşinci zamanda dikim yapılan Alegria çeşidinden alındığ 1 görülmektedir. Çalışmanın ikinci yılında ise, en yüksek bitki başına ortalama yumru verimi $1042.20 \mathrm{~g} \mathrm{bitki}^{-1}$ ile Alegria çeşidinden üçüncü dikim zamanında alınırken, en düşük bitki başına ortalama yumru verimi $228.20 \mathrm{~g}_{\text {bitki }}{ }^{-1}$ ile beşinci dikim zamanında Borwina çeşidinden alınmıştır (Tablo 5).

\subsection{Bitki başına yumru sayısı}

Bazı patates çeşitlerinde farklı dikim zamanlarının verim üzerindeki etkisinin incelendiğ çalışmada, bitki başına yumru sayısı değerlerine ilişkin veriler Tablo 6'da verilmiştir. Yıllar ayrı ayrı değerlendirildiğinde, 2017 y1lında, bitki başına yumru sayısı yönünden çeşit ve dikim zamanları arasında istatistiki olarak $\mathrm{p}<0.01$ düzeyinde önemli farklılık bulunmuştur. Bitki başına yumru sayısı bakımından; çeşitler arasında en yüksek değer 15.92 adet bitki ${ }^{-1}$ ile Soraya çeşidinden, en düşük değerler ise Alegria (11.90 adet bitki $\left.{ }^{-1}\right)$ ve Borwina (12.58 adet bitki ${ }^{-1}$ ) çeşitlerinden alınmıştır. Dikim zamanlarına bakıldığında, çeşitlerin ortalaması olarak, en yüksek bitki başına yumru sayısı 20.34 adet bitki $^{-1}$ ikinci dikim zamanından, en düşük değer ise 9.21 adet bitki $^{-1}$ ile beşinci dikim zamanından alındığı görülmektedir. İkinci dikim zamanından sonra tüm çeşitlerde dikim zamanı geciktikçe bitki başına yumru sayısı değerlerinin azaldığı, ancak bazı çeşitlerin farklı dikim zamanlarındaki performanslarının benzerlik gösterdiği görülmüştür. Bu nedenle 2017 yılında çeşit $\mathrm{x}$ dikim zamanı interaksiyonu istatistiki açıdan çok önemli $(\mathrm{p}<0.01)$ çıkmıştır (Tablo 6).

Tablo 6'daki 2018 yılı verileri ele alındığında, bitki başına yumru sayısı bakımından çeşitler arasındaki fark $\mathrm{p}<0.01$, dikim zamanları arasındaki fark $\mathrm{p}<0.05$ seviyesinde önemli çıkarken, çeşit $\mathrm{x}$ dikim zamanı interaksiyonu önemli bulunmamıştır. Dikim zamanlarının ortalaması olarak, en yüksek bitki başına yumru sayısı istatistiki olarak aynı grupta yer alan Soraya (8.33 adet bitki $\left.{ }^{-1}\right)$ ve Alegria (7.82 adet bitki $\left.{ }^{-1}\right)$ çeşitlerinden elde edilmiştir. Dikim zamanları bakımından ise, istatistiki olarak önemli farklılık 5. DZ ile diğer dikim zamanları arasında gerçekleşmiş olup; en yüksek bitki başına yumru sayısı birinci ve ikinci dikim zamanlarından (sırasiyla, 8.82 adet bitki ${ }^{-1}$ ve 8.32 adet bitki ${ }^{-1}$ ) elde edilmiştir (Tablo 6).

\subsection{Ortalama yumru ağırlığı}

Ortalama yumru ağırlı̆̆ verileri incelendiğinde, her iki yılda da çeşitler ve dikim zamanlarının ortalama yumru ağırlığı üzerine etkisi istatistiki 
Tablo 6. Farklı patates çeşitlerinde dikim zamanlarına göre belirlenen bitki başına yumru sayısı (adet bitki $\left.{ }^{-1}\right)^{1}$

\begin{tabular}{|c|c|c|c|c|c|c|c|}
\hline \multirow{2}{*}{ Y1l } & \multirow{2}{*}{ Çeşitler } & \multicolumn{5}{|c|}{ Dikim zamanı } & \multirow{2}{*}{ Ortalama } \\
\hline & & 1 & 2 & 3 & 4 & 5 & \\
\hline \multirow{4}{*}{2017} & Alegria & $13.16 \mathrm{c}-\mathrm{e}$ & $19.81 \mathrm{~b}$ & $11.63 \mathrm{efg}$ & $9.84 \mathrm{fg}$ & $5.08 \mathrm{~h}$ & $11.90 \mathrm{~b}$ \\
\hline & Borwina & $11.62 \mathrm{fg}$ & $16.81 \mathrm{c}$ & $14.62 \mathrm{cde}$ & $10.36 \mathrm{fg}$ & $9.47 \mathrm{~g}$ & $12.58 \mathrm{~b}$ \\
\hline & Soraya & $12.72 \mathrm{~d}-\mathrm{f}$ & $24.39 \mathrm{a}$ & $15.97 \mathrm{~cd}$ & $13.41 \mathrm{cde}$ & $13.08 \mathrm{def}$ & $15.92 \mathrm{a}$ \\
\hline & Ortalama & $12.50 \mathrm{BC}$ & $20.34 \mathrm{~A}$ & $14.07 \mathrm{~B}$ & $11.21 \mathrm{BC}$ & $9.21 \mathrm{C}$ & 13.46 \\
\hline & $\mathrm{LSDC}_{\mathrm{C}}=1.3$ & $\mathrm{D}_{\mathrm{DZ}}=2.57$ & $\mathrm{D}_{\mathrm{C} x \mathrm{xZ}}=2$. &, $\mathrm{VK}=\% 1$ & & & \\
\hline \multirow{4}{*}{2018} & Alegria & 9.74 & 8.29 & 7.00 & 7.53 & 6.53 & $7.82 \mathrm{a}$ \\
\hline & Borwina & 7.03 & 6.83 & 7.18 & 5.95 & 5.20 & $6.44 \mathrm{~b}$ \\
\hline & Soraya & 9.70 & 9.85 & 8.58 & 7.85 & 5.65 & $8.33 \mathrm{a}$ \\
\hline & Ortalama & $8.82 \mathrm{~A}$ & $8.32 \mathrm{~A}$ & $7.58 \mathrm{AB}$ & $7.11 \mathrm{AB}$ & $5.79 \mathrm{~B}$ & 7.53 \\
\hline
\end{tabular}

1: Aynı grupta, aynı satırda ve aynı sütunda farklı harfle gösterilen ortalamalar arasındaki farklılık istatistiki açıdan önemlidir, DZ: Dikim zamanı, VK: Varyasyon katsayısı, ${ }^{*}: \mathrm{p}<0.05$ seviyesinde önemli, ${ }^{* *}: \mathrm{p}<0.01$ seviyesinde önemli, Ö.D.: Önemli değil

olarak p $<0.01$ seviyesinde önemli olmuştur. Dikim zamanlarının ortalaması olarak, en yüksek ortalama yumru ağırlığı her iki yılda da Alegria çeşidinden (sırasıyla 69.86 g ve 94.36 g) elde edilmiştir. Soraya çeşidi yine her iki yılda da en düşük ortalama yumru ağırlığını vermiştir. Dikim zamanları incelendiğinde; çeşitlerin ortalaması olarak en yüksek ortalama yumru ağırlığı her iki yılda da üçüncü dikim zamanından (sırasıyla, $92.99 \mathrm{~g}$ ve $114.81 \mathrm{~g})$ alınmıştır. Çalışmada dikim zamanları içerisinde en düşük ortalama yumru ağırlığı değerleri her iki yılda da beşinci dikim zamanında belirlenmiştir (Tablo 7).
Çalışmanın ikinci yılında, ortalama yumru ağırlı̆̆ 1 yönünden çeşit $\mathrm{x}$ dikim zamanı interaksiyonu istatistiki olarak çok önemli çıkmıştır. Bunun nedeni olarak; ortalama yumru ağırlı̆̆ı değerlerinin genel olarak tüm çeşitlerde üçüncü dikim zamanına kadar benzer artışlar göstermesi, buna karş11ık üçüncü dikim zamanından sonra bazı çeşitlerin ortalama yumru ağırlıklarının diğer bazı çeşitlere göre daha fazla düşüş göstermesinin, bir başka ifade ile çeşitlerin farklı dikim zamanlarında ortalama yumru ağırlığı yönünden farklı performans göstermesinin etkili olması söylenebilir (Tablo 7).

Tablo 7. Farklı patates çeşitlerinde dikim zamanlarına göre belirlenen ortalama yumru ağırlığı $(\mathrm{g})^{1}$

\begin{tabular}{|c|c|c|c|c|c|c|c|}
\hline \multirow{2}{*}{ Y11 } & \multirow{2}{*}{ Çeşitler } & \multicolumn{5}{|c|}{ Dikim zamanı } & \multirow{2}{*}{ Ortalama } \\
\hline & & 1 & 2 & 3 & 4 & 5 & \\
\hline \multirow{5}{*}{2017} & Alegria & 62.09 & 71.84 & 105.52 & 73.72 & 36.14 & $69.86 \mathrm{a}$ \\
\hline & Borwina & 45.64 & 76.46 & 95.74 & 63.68 & 27.24 & $61.75 \mathrm{~b}$ \\
\hline & Soraya & 53.07 & 65.53 & 77.72 & 64.27 & 27.75 & $57.67 \mathrm{~b}$ \\
\hline & Ortalama & $53.60 \mathrm{C}$ & $71.28 \mathrm{~B}$ & $92.99 \mathrm{~A}$ & $67.22 \mathrm{BC}$ & $30.37 \mathrm{D}$ & 63.09 \\
\hline & $\mathrm{LSD}_{\mathrm{C}}=6$ & $\mathrm{D}_{\mathrm{DZ}}=16.83$ & $\mathrm{SD}_{\mathrm{C} x \mathrm{DZ}}=\mathrm{O}$ &, $\mathrm{VK}=\% 16$ & & & \\
\hline \multirow{5}{*}{2018} & Alegria & $80.64 \mathrm{de}$ & $89.35 \mathrm{cde}$ & $139.26 \mathrm{a}$ & $118.00 \mathrm{ab}$ & $44.54 \mathrm{f}$ & $94.36 \mathrm{a}$ \\
\hline & Borwina & $94.06 \mathrm{~cd}$ & $91.84 \mathrm{~cd}$ & $102.42 b c$ & $101.36 \mathrm{bcd}$ & $38.38 \mathrm{f}$ & $85.61 \mathrm{ab}$ \\
\hline & Soraya & $86.86 \mathrm{cde}$ & $91.23 \mathrm{~cd}$ & $102.75 \mathrm{bc}$ & $68.51 \mathrm{e}$ & $39.70 \mathrm{f}$ & $77.81 \mathrm{~b}$ \\
\hline & Ortalama & $87.19 \mathrm{~B}$ & $90.81 \mathrm{~B}$ & $114.81 \mathrm{~A}$ & $95.96 \mathrm{~B}$ & $40.87 \mathrm{C}$ & 85.93 \\
\hline & $\mathrm{LSD}_{\mathrm{C}}=9$ & $\mathrm{D}_{\mathrm{DZ}}=17.62$ & $\mathrm{SD}_{\mathrm{C} x \mathrm{xZ}}=2$ & $8^{* *}, V K=\%$ & & & \\
\hline
\end{tabular}

': Aynı grupta, aynı satırda ve aynı sütunda farklı harfle gösterilen ortalamalar arasındaki farklılık istatistiki açıdan önemlidir, DZ: Dikim zamanı, VK: Varyasyon katsayısı, **: ${ }^{*}<0.01$ seviyesinde önemli, Ö.D.: Önemli değil

\section{Tartışma ve Sonuç}

İki yıla ait sonuçlar incelendiğinde; yumru verimlerinin, hem dikim zamanlarına hem de yıllara göre ciddi farklılık gösterdiği görülmüştür. Bunda iklim faktörlerinin etkili olduğu düşünülmektedir. Nitekim Tablo 2'den de görüleceği üzere, patates dikim zamanı düşük (Şubat) veya yüksek (Nisan, Mayıs) sıcaklıklara denk geldiğinde; bitki başına yumru sayısı (Tablo 6), yumru ağırlığı (Tablo 5) ve dolayısıyla yumru verimi (Tablo 4) olumsuz etkilenmiştir. Benzer şekilde, sıcaklık farklılığının (Tablo 2) yıllar arasında oluşan verim farklılığına da etkisi olmuş; bunun sonucunda da yumru verimi ve incelenen diğer parametreler yönünden birinci y1l değerleri, ikinci yıla göre daha yüksek bulunmuştur. Farklı ekolojilerde yapılan birçok araştırmada, patates bitkisinde verim üzerine iklimin ve çevresel faktörlerin etkili olduğu, çeşitlere göre değişmekle birlikte verim yönünden yıllar arasında önemli farklılıkların oluşabileceği rapor edilmiştir (Ali ve ark., 2010; Arığlu ve ark., 2010; Çalışkan ve ark., 2010b; Singh ve ark., 2010). Yüksek sicaklık ve uzun gün periyodu, yumru oluşumlarının başlangıcını ve yumru büyümesini yavaşlattığı, kısa gün 1şı̆̆ı periyodundaki (12 saat) 
düşük sıcaklık ortalamaları $\left(15-19^{\circ} \mathrm{C}\right)$ erken yumru oluşumu için oldukça uygun olduğu, sıcaklıklardaki küçük artışların dahi kuru madde birikimini azalttığı bildirilmektedir (Van Dam ve ark., 1996). Van koşullarında yapılan bir çalışmada, dekara yumru verimlerinin dikim zamanlarına bağlı olarak 1786.6-1812.7 $\mathrm{kg} \mathrm{da}^{-1}$ arasında değiştiği rapor edilmiştir (Yıldırım ve ark., 2005). Bafra ekolojik koşullarında iki farklı patates çeşidi ile yapılan bir başka çalışmada ise; dikim zamanının gecikmesine paralel olarak dekara yumru veriminin ve yumru iriliğinin arttığı, 25 Nisan tarihinde yapılan dördüncü dikimlerde verimin düştüğü, bu düşüşün de sıcaklığın $20 \quad{ }^{\circ} \mathrm{C}$ 'nin üzerine çıkmasından kaynaklandığı ve çeşitlerin ve yumru ön uygulamalarının ortalaması olarak dikim zamanlarına göre patates verimlerinin 880.4-2828.7 $\mathrm{kg} \mathrm{da}^{-1}$ arasında değiştiği bildirilmektedir (Karaca Öner ve Aytaç, 2016).

Araştırmamızda; yumru verimi ve yumru verimine etkili olan bitki başına yumru sayısı, bitki başına yumru ağırlığg ile ortalama yumru ağırlığ1 değerleri yönünden, incelenen çeşitler arasında anlamlı farklılıklar görülmüştür. Çeşitler arasındaki bu farklılığın sebebi; çeşitlerin genetik yapılarının farklı olmasından kaynaklanması ve bu çeşitlerin yetiștirme ortamlarından belirgin şekilde farklı olarak etkilenmesi ile açıklanabilir. Palta (2010), sıcaklık stresinin; çeşitlere bağlı olarak farklı tepkiler ortaya çıkmasına neden olduğu, genelde bitki büyümesini ve yumru oluşumunu olumsuz etkilediğini bildirmiştir. Benzer şekilde; Allen ve ark. (2009), yumru verimlerinin sicaklik değişimlerinden etkilendiğini ve çeşitlerin de sıcaklık değişimlerine farklı tepkiler gösterdiğini bildirmişlerdir. Farklı ekolojilerde yapılan bir çok çalışmalarda, kullanılan çeşitlere göre yumru verimlerinin, örneğin; Bafra Ovası ekolojisinde 1507-3144 kg da ${ }^{-1}$ (Deniz ve Özdemir, 1979; Arslan ve Kevseroğlu, 1991), Ordu ekolojik koşullarında 1390-2840 kg da ${ }^{-1}$ (Dede, 2004); Erzurum ekolojisinde 1495.9-3220.9 kg da-1 (Kara, 2016) arasında değiştiği belirlenmiştir. Başka bir çalışmada ise (Allen, 2009) farklı çeşitlerde verim ve verimi etkileyen bazı unsurların dikim zamanlarına bağlı olarak değişiklik gösterdiği bildirilmiştir. Van yöresinde 21 farklı patates çeşidi ile yapılan bir araştırmada, araştırmamız bulgularına benzer şekilde, yumru verimlerinin yıllar arasında farklılık gösterdiği ve farklı yıllarda farklı çeşitlerin öne çıktığı rapor edilmiştir (Arslan ve ark., 2002).

Siirt ekolojisinde yapılan bu araştırmanın sonucunda, patates tarımında dikim zamanının ve çeşit seçiminin verim üzerinde çok önemli bir etkiye sahip olduğu; en yüksek verimlerin Mart ayı içerisinde yapılan dikimlerden alınabileceği tespit edilmiştir. Turfanda patates yetiştiriciliğinde, Siirt ili ve benzeri iklim koşullarında çeşit seçiminde önceliğin "Soraya" çeşidine verilmesi gerektiği, çeşidin temin edilememesi durumunda ise alternatif olarak "Alegria" çeşidinin de rahatlıkla dikilebileceği sonucuna varılmıştır.

\section{Teşekkür}

Araştırmada, bitkisel materyallerin teminini sağlayan ve çalışmayı destekleyen Doğa Tohumculuk'a ve Ziraat Yüksek Mühendisi Mete Kağan BÜLBÜL'e teşekkür ederim.

\section{Kaynaklar}

Ali, M.A., El Amen, S.D.M., El Mahdi, A.R.A., 2010. Effect of cultural practices on performance of potato grown on clay soils of the tropical conditions of Northern Sudan. Proceedings of the Potato AgroPhysiology, 20-24 September, Nevsehir, Turkey, pp. 60-68.

Allen, E.J., 2009. Effects of date of planting on growth and yield of contrasting potato varieties in Pembrokeshire. The Journal of Agricultural Science, 89(3): 711-735.

Allen, E.J., Bean, J.N., Griffith, R.L., O’Brien, P.J., 2009. Effects of length of sprouting period on growth and yield of contrasting early potato varieties. The Journal of Agricultural Science, 92(1): 151-163.

Anonim, 2001. Tarımsal Değerleri Ölçme Denemeleri Teknik Talimat1, Patates (Solanum tuberosum L.). T.C. Tarım ve Köyişleri Bakanlığı Tohumluk Tescil ve Sertifikasyon Merkezi Müdürlüğü, Ankara. (https://www.tarimorman.gov.tr/BUGEM/TTSM/Be lgeler/Tescil/Teknik\%20Talimatlar/End\%C3\%BC stri\%20Bitkileri/pates.pdf), (Erişim tarihi: 26.02.2019).

Anonymous, 2018. International Year of the Potato 2008. (http://www.fao.org/potato-2008/en/potato/cultivati on.html), (Erişim tarihi: 25.10.2018).

Anonymous, 2019. FAOSTAT. (http://www.fao.org/ faostat/en/\#data/QC), (Erişim tarihi: 08.01.2019).

Arıŏlu, H., Kurt, C., Güllüoğlu, L., Zaimoğlu, B., Onaran, H., 2010. The determination of yield performance of some potato varieties in mediterranean climate conditions. Proceedings of the Potato AgroPhysiology, 20-24 September, Nevsehir, Turkey, pp. 302-306.

Arslan, B., Kevseroğlu, K., 1991. Bitki sıklığının bazı patates (Solanum tuberosum L.) çeşitlerinin verimi ve önemli özelliklerine etkileri üzerinde bir araştırma. Yüzüncü Yll Üniversitesi Ziraat Fakültesi Dergisi, 1(3): 89-111.

Arslan, B., Tunçtürk, M., Eryiğit, T., Ekin, Z., Kaya, A.R., 2002. Van Erciş'te bazı patates genotiplerinin verim ve verim komponentlerinin belirlenmesi. III. Ulusal Patates Kongresi, 23-27 Eylül, Bornovaİzmir, s. 381-391.

Çalışkan, M.E., Onaran, H., Arıŏlu, H., 2010a. The overview to the Turkish potato sector: Challenges, 
achievements and expectations. Proceedings of the Potato AgroPhysiology, 20-24 September, Nevsehir, Turkey, pp. 1-10.

Çalışkan, M.E., Kusman, N., Çalışkan, S., 2010b. Growth and yield performance of different sized seed tubers derived from true potato seed (tps) in contrasting. Proceedings of the Potato AgroPhysiology, 20-24 September, Nevsehir, Turkey, pp. 230-240.

Dede, Ö., 2004. Ordu ekolojik koşullarında değişik olumlu patates çeşitlerinin (Solanum tuberosum L.) bazı agronomik ve teknolojik özelliklerinin belirlenmesi. Atatürk Üniversitesi Ziraat Fakültesi Dergisi, 35(3-4): 159-164.

Deniz, N., Özdemir, O., 1979. Bafra ve Çarşamba Ovaları koşullarında yetiştirilecek patates çeşitleri. (Mülga) Köyişleri ve Kooperatifler Bakanlığı, Topraksu Genel Müdürlüğü, Samsun Bölge Topraksu Araştırma Enstitüsü Müdürlüğü Yayınları, Genel Yayın No: 14, Rapor Yayın No: 12, s. 1-31.

Kara, K., 2016. Bazı patates çeşitlerinin erzurum şartlarında performanslarının belirlenmesi. Atatürk Üniversitesi Ziraat Fakültesi Dergisi, 47(2): 95-99.

Karaca Öner, E., Aytaç, S., 2016. Bafra koşullarında turfanda patates (Solanum tuberosum L.)'te dikim zamanları ve yumru ön uygulamalarının verim ve verim kriterlerine etkisi. Ordu Üniversitesi Bilim ve Teknoloji Dergisi, 6(2): 184-194.

Khan, A.A., Jilani, M.S., Khan, M.Q., Zubair, M., 2011. Effect of seasonal variation on tuber bulking rate of potato. The Journal of Animal \& Plant Sciences, 21(1): 31-37.

Kolsarıc1, Ö., 2011. Tarla Bitkileri Kitabı. Ankara Üniversitesi Ziraat Fakültesi, Yayın No: 1588, Ders Kitabi: 540, Ankara.

Palta, J.P., 2010. Improving potato tuber quality and production by targeted calcium nutrition: The discovery of tuber roots leading to a new concept in potato nutrition. Proceedings of the Potato
AgroPhysiology, 20-24 September, Nevsehir, Turkey, pp. 11-18.

Rowe, C.R., 1993. Potato Health Manegement. Department of Plant Pathology. Ohio State University, USA.

Samanc1, B., Özkaynak, E., Çetin, M.D., 2003. Antalya koşullarında turfanda patates (Solanum tuberosum L.) yetiştiriciliğinde bazı çeşitlerin verim ve verim ile ilgili özelliklerinin belirlenmesi. Akdeniz Üniversitesi Ziraat Fakültesi Dergisi, 16(1): 27-33.

Singh, S.V., Kadian, M.S., Patel, N.H., Luthra, S.K., Carli, C., Pandey, S.K., Kumar, D., Kumar, P., Sharma, N., Bonierbale, M., Gopal, J., Singh, B.P., 2010. Evaluation of CIP advanced clones for hot climate in gujarat state. Proceedings of the Potato AgroPhysiology, 20-24 September, Nevsehir, Turkey, pp. 84-89.

Tunçtürk, M., 2006. Van koşullarında bazı patates (Solanum tuberosum L.) çeşitlerinin yumru kalibrasyonu ve kalite özelliklerinin belirlenmesi. Selçuk Üniversitesi Ziraat Fakültesi Dergisi, 20(39): 63-70.

Van Dam, J., Kooman, P.L., Struiki, P.C., 1996. Effects of temperature and photoperiod on early growth and final number of tubers in potato (Solanum tuberosum L.). Potato Research, 39(1): 51-62.

Yıldırım, B., Tunçtürk, M., Çiftçi, C., 2005. Değişik dikim zamanlarının farklı patates (Solanum tuberosum L.) çeşitlerinde verim ve verim unsurları üzerine etkisi. Yüzüncü Yll Üniversitesi Ziraat Fakültesi Tarım Bilimleri Dergisi, 15(1): 1-9.

Yılmaz, H., Demircan, V., Erel, G., 2006. Bazı önemli patates üreticisi illerde patates üretim maliyeti ve gelirinin karşılaştırmalı olarak incelenmesi. Süleyman Demirel Üniversitesi Ziraat Fakültesi Dergisi, 1(1): 22-32.

Yurtsever, N., 1984. Deneysel İstatistik Metotları. Tarım Orman ve Köy İşleri Bakanlığı, Köy Hizmetleri Genel Müdürlüğü Yayınları, Ankara. 